\title{
HUBUNGAN PEMBERIAN INSENTIF DENGAN KINERJA PERAWAT DALAM PENDOKUMENTASIAN ASUHAN KEPERAWATAN
}

\author{
Masri Saragih, Rosetty Sipayung, Eva Kartika Hasibuan \\ Program Studi Ners Fakultas Farmasi dan Ilmu Kesehatan, Universitas Sari Mutiara Indonesia \\ E-mail : masri_saragih@ymail.com
}

\begin{abstract}
The problem that often arises in the implementation of nursing care is that many nurses have not done a complete documentation of nursing care. The provision of incentives is one of the factors that influence the performance of nurses in documentation. This study aimed to identify the relationship between incentives and nurses' performance in documenting nursing care at Sari Mutiara Lubuk Pakam Hospital. The research design used a description of the correlation with the cross sectional approach. The population in the study were 56 nurses in the inpatient room. There were 56 respondents as total sampling for the sampling technique. Data collection tools used questionnaire sheets and observation sheets. The statistical test used the chi square test. The results of the univariate analysis for the incentive variable the majority of incentives were classified as high as $69,6 \%$ and the performance of nurses in the complete documentation was $67.8 \%$. From the results of the bivariate analysis showed that there was a relationship between the provision of incentives and the performance of nurses in documenting nursing care $(p=0.017 ; p<0.05)$. It is hoped that nurses will be able to complete documentation not only because of a high incentive, but it is a nurse's responsibility that must be carried out.
\end{abstract}

Keywords: Incentives, Nurse Performance, Documentation

\begin{abstract}
Abstrak
Masalah yang sering muncul dalam pelaksanaan asuhan keperawatan adalah banyak perawat yang belum melakukan pendokumentasian asuhan keperawatan secara lengkap. Pemberian insentif merupakan salah satu faktor yang mempengaruhi kinerja perawat dalam pendokumentasian. Penelitian ini bertujuan untuk mengidentifikasi hubungan pemberian insentif dengan kinerja perawat dalam pendokumentasian asuhan keperawatan di Rumah Sakit Umum Sari Mutiara Lubuk Pakam. Desain penelitian yang digunakan adalah deskripsi korelasi dengan pendekatan cross sectional. Populasi dalam penelitian adalah seluruh perawat di ruang rawat inap sebanyak 56 orang. Teknik pengambilan sampel total sampling sehingga sampel sebanyak 56 responden. Alat pengumpulan data menggunakan lembar kuesioner dan lembar observasi. Uji statistik yang digunakan uji chi square. Hasil dari analisa univariat untuk variabel pemberian insentif mayoritas pemberian insentif tergolong tinggi sebanyak $69,6 \%$ dan kinerja perawat dalam pendokumentasian lengkap $67,8 \%$. Dari hasil analisa bivariat yang digunakan menunjukkan bahwa ada hubungan pemberian insentif dengan kinerja perawat dalam pendokumentasian asuhan keperawatan $(p=0,017$ ; $\mathrm{p}<0,05$ ). Diharapkan agar perawat mampu melakukan pendokumentasian yang lengkap bukan hanya karena adanya suatu insentif yang tinggi, tetapi menjadi suatu tanggung jawab perawat yang harus dilaksanakan.
\end{abstract}

Kata Kunci:Pemberian Insentif, Kinerja Perawat, Pendokumentasian 


\section{PENDAHULUAN}

Kemampuan rumah sakit memberikan pelayanan asuhan keperawatan secara professional sangat tergantung kinerja perawat dalam menerapkan standar asuhan keperawatan. Standar asuhan keperawatan merupakan pedoman atau tolak ukur kualitas dalam pelaksanaan praktek pelayanan keperawatan (Nursalam, 2008).

Pelayanan keperawatan diberikan kepada pasien dalam bentuk kinerja perawat dan harus didasari kemampuan yang tinggi. Kinerja merupakan suatu hasil kerja seseorang yang dilakukan sesuai dengan tugasnya di dalam suatu organisasi (Nursalam, 2011). Dalam menilai kinerja perawat digunakan standar praktek keperawatan yangmerupakan pedoman bagi perawat dalam melaksanakan asuhan keperawatan. Instrumen evaluasi penerapan standar asuhan keperawatan (SAK) pada pedoman studi dokumentasi asuhan keperawatan yang meliputi pengkajian, diagnosa, perencanaan, tindakan, evaluasi dan catatan asuhan keperawatan (Depkes 2005)

Masalah yang sering muncul dan dihadapi di Indonesia dalam pelaksanaan asuhan keperawatan adalah banyak perawat yang belum melakukan pelayanan sesuai pendokumentasian asuhan keperawatan.

Data yang didapatkan Di Rumah Sakit Umum Daerah Banyumas sebanyak 40 perawat $(52,6 \%)$ memiliki kinerja pendokumentasian baik, sedangkan sebanyak 36 perawat $(47,4 \%)$ memiliki kinerja pendokumentasian kurang (Pramithasari 2016). Sedangkan di RSUD Jakarta dengan melakukan pengukuran kelengkapan dokumentasi menggunakan instrumen Depkes didapatkan, dari 95 dokumen asuhan keperawatan $71,6 \%$ dokumentasi asuhan keperawatan belum lengkap (Siswanto, 2013).

Kinerja perawat dalam pelaksanaan pendokumentasian asuhan keperawatan dipengaruhi oleh beberapa faktor yaitu kompetensi sumber daya manusia, budaya organisasi, dan sistem reward termasuk insentif(Sudarmanto, 2009).
Insentif merupakan suatu faktor pendorong bagi pegawai untuk bekerja lebih baik agar kinerja pegawai dapat meningkat. Pada hasilpenelitian yang dilakukan oleh Hasmi (2018) bahwa insentif memiliki hubungan terhadap pendokumentasian asuhan keperawatan.

Penelitian sebelumnya yang dilakukan oleh Retyaningsih (2013) bahwa motivasi perawat yang tidak baik cenderung kualitas dokumentasi juga tidak baik. Serta penelitian yang dilakukan oleh Bara M \& Suryati (2014) bahwa motivasi yang didapatkan perawat pelaksana berpengaruh terhadap pendokumentasian asuhan keperawatan.

Berdasarkan hasil observasi pada 5 status asuhan keperawatan di Rumah sakit Sari Mutiara, didapatkan bahwa 1 status asuhan keperawatan pada bagian form pengkajian tidak terisi sesuai dengan format pengkajian yang ada, 2 status asuhan keperawatan pada diagnose keperawatan tidak terdokumentasinya diagnosa keperawatan berdasarkan analisa data, serta tidak terdokumentasinya prioritas masalah pada pasien dan pada 1 status keperawatan pasien yang lainnya terdapat pengisian catatan perkembangan pasien yang kosong pada salah satu shift. Berdasarkan hasil wawancara terhadap 4 orang perawat mereka mengatakan pemberian insentif di rumah diberikan per tiga bulan sekali dalam bentuk materil.

Berdasarkan uraian di atas, rumusan masalah dalam penelitian ingin mengetahui hubungan pemberian insentif dengan kinerja perawat dalam melakukan asuhan keperawatan

\section{METODE PENELITIAN}

Penelitian ini menggunakan jenis penelitian deskriptif korelasi. Desain penelitian yang digunakan dalam penelitian ini adalah cross sectional yaitu penelitian yang menekankan waktu pengukuran data variable independen dan dependen hanya satu kali pada suatu saat. Oleh karena itu peneliti melakukan penilaian variable pemebrian 
insentif maupun variable kinerja perawat hanya satu kali tanpa ada tindaklanjut.

Populasi dalam penelitian ini adalah seluruh perawat pelaksana rawat inap yang ada. Total populasi berjumlah 56 perawat. Pengambilan sampel dalam penelitian ini menggunakan tekhnik total sampling.

Alat pengumpulan data yang digunakan dalam penelitian ini menggunkaan instrument penelitian yang terdiri dari tiga bagian instrument yaitu demografi yang berhubungan dengan karakteristik responden terdiri dari jeniskelamin, Pendidikan dan lama bekerja. Kuesioner pemberian insentif merupakan kuesioner yang diadopsi dari peneliti sebelumnya Nugroho (2008) dan telah dilakukan uji validitas dan reliabilitas, dengan nilai cronbach's alpha 0,848 . Bentuk kuesioner multiple choice dengan 12 pernyataan dengan 4 alternatif pilihan jawaban. Respon akan mengisi kuesioner dengan memberikan tanda $\sqrt{ }$ pada pilihan jawaban yang dianggap paling sesuai. Angka tertinggi dari keseluruhan pernyataan merupakan kecenderungan pemberian instentif responden.

Sedangkan alat pengumpulan data untuk mengukur kinerja perawat dalam pendokumentasian asuhan keperawatan menggunakan lembar observasi menurut Depkes (2005).

Penelitian ini dilakukan setelah mendapat izin dari Direktur rumah sakit untuk melakukan penelitiand i lingkungan rumah sakit. Sebelum penelitian dilakukan, semua responden yang menjad isubyek penelitian diberi informasi tentang rencana dan tujuan penelitian melalui pertemuan resmi dan tertulis. Setiap responden diberi hak penuh untuk menyetujui atau menolak menjadi responden dengan cara menandatangani informed concent atau surat pernyataan kesedian yang telah disiapkan oleh peneliti.

Etika penelitian yang dilakukan pada saat penelitian terhadap subjek penelitian meliputi privasi dihormati, anonimitas dipertahankan sedangkan data penelitian akan dijaga kerahasiannya dimana akses hanya ada pada peneliti dan jika data tersebut sudah selesai digunakan maka data tersebut akan dimusnahkan. Pengolahan data dan Analisa data yang dilakukan peneliti menggunakan bantuan software computer yaitu SPSS versi 17.

\section{HASIL PENELITIAN}

Tabel 1: KarakteristikResponden

\begin{tabular}{|c|c|c|c|}
\hline \multicolumn{2}{|c|}{ Karakteristik Respoden } & $\mathbf{n}$ & $\%$ \\
\hline \multirow{2}{*}{$\begin{array}{l}\text { Jenis } \\
\text { Kelamin }\end{array}$} & Laki-laki & 7 & 12,5 \\
\hline & Perempuan & 49 & 87,5 \\
\hline \multirow[t]{3}{*}{ Pendidikan } & SPK & 4 & 7,14 \\
\hline & D3 & 50 & 89,29 \\
\hline & Ners & 2 & 3,57 \\
\hline \multirow[t]{2}{*}{ Masa Kerja } & $<1$ Tahun & 8 & 14,29 \\
\hline & $>1$ Tahun & 48 & 85,71 \\
\hline
\end{tabular}

Berdasarkan tabel 1 menunjukkan karakteristik responden. Pada karakteristik jenis kelamin menunjukkan $87,5 \%$ responden adalah perempuan, pada karakteristik Pendidikan menunjukkan 89,29\% Pendidikan responden adalah D3 dan pada karakteristik masa kerja $85,71 \%$ responden memiliki masa kerja $>1$ tahun.

Tabel 2: Pemberian Insentif

\begin{tabular}{llcc}
\hline Karakteristik & Kategori & n & \% \\
\hline Pemberian & Rendah & 17 & 30,4 \\
\cline { 2 - 4 } Insentif & Tinggi & 39 & 69,6 \\
\hline & Total & 56 & 100 \\
\hline
\end{tabular}

Berdasarkan Pemberian Insentif mayoritas responden menilai pemberian insentif tergolong tinggi sebanyak $69,6 \%$.

Tabel 3: Kinerja Perawat Dalam Pendokumentasian

\begin{tabular}{llcc}
\hline Karakteristik & Kategori & n & \% \\
\hline $\begin{array}{l}\text { Kinerja Perawat } \\
\text { dalam }\end{array}$ & $\begin{array}{l}\text { Tidak } \\
\text { lengkap }\end{array}$ & 18 & 32,2 \\
\cline { 2 - 4 } pendokumentasian & Lengkap & 38 & 67,8 \\
\hline & Total & 56 & 100 \\
\hline
\end{tabular}

Berdasarkan Kinerja Dalam Pendokumentasian Asuhan Keperawatan bahwa mayoritas responden sudah melakukan pendokumentasian secara lengkap sebanyak $69,78 \%$. 
Tabel 4: Hubungan Pemberian Insentif Dengan Kinerja Perawat Dalam Pendokumentasian

\begin{tabular}{|c|c|c|c|c|c|c|c|}
\hline \multirow{3}{*}{$\begin{array}{l}\text { Pemberian } \\
\text { Insentif }\end{array}$} & \multicolumn{4}{|c|}{ Kinerja Perawat } & \multirow{2}{*}{\multicolumn{2}{|c|}{ Jumlah }} & \multirow[b]{2}{*}{$\mathbf{P}$} \\
\hline & \multicolumn{2}{|c|}{$\begin{array}{c}\text { Tidak } \\
\text { Lengkap }\end{array}$} & \multicolumn{2}{|c|}{$\begin{array}{c}\text { Lengk } \\
\text { ap }\end{array}$} & & & \\
\hline & $\mathrm{n}$ & $\%$ & $\mathrm{~N}$ & $\%$ & $\mathrm{n}$ & $\%$ & \multirow{3}{*}{$\begin{array}{l}0,0 \\
17\end{array}$} \\
\hline Rendah & 11 & 19,7 & 6 & 10,7 & 17 & 30,4 & \\
\hline Tinggi & 7 & 12,5 & 32 & 57,1 & 39 & 69,6 & \\
\hline Total & 18 & 32,2 & 38 & 67,8 & 56 & 100 & \\
\hline
\end{tabular}

Dari hasil penelitian didapatkan bahwa responden yang menilai pemberian insentif tergolong rendah sebanyak 30,4\% dengan kinerja dalam pendokumentasian tidak lengkap $19,7 \%$ dan lengkap $10,7 \%$. Sedangkan responden menilai pemberian insentif tergolong tinggi $69,6 \%$ dengan pendokumentasian tidak lengkap $12,5 \%$ dan lengkap 57,1\%. Hasil penelitian menunjukkan bahwa ada hubungan antara Pemberian Insentif Dengan Kinerja Perawat Dalam Pendokumentasian Asuhan Keperawatan dengan nilai $\mathrm{p}$ value 0,017 $(\mathrm{p}<0,05)$.

\section{PEMBAHASAN}

\section{Pemberian insentif}

Hasil penelitian yang dilakukan menunjukkan mayoritas responden menilai bahwa insentif yang diberikan tergolong tinggi $69,6 \%$. Dalam sebuah instansi termasuk rumah sakit diperlukan adanya pemberian reward berupa insentif kepada pegawai salah satunya perawat. Insentif yang diberikan dapat dalam bentuk materil, seperti uang maupun barang, dan bentuk non materil berupa gelar, medali, piagam, pujian (Sarwoto, 2010).

Insentif yang diterima perawat diberikan dalam jangka waktu yang telah ditentukan suatu rumah sakit. Insentif juga dapat diberikan secara individu, hanya satu perawat yang akan diberikan insentif dikarenakan suatu hal sehingga hanya perawat tersebut yang pantas untuk menerimanya. Suatu insentif juga dapat diberikan dalam satu tim, dikarenakan tim tersebut mampu mencapai tujuan maupun target yang diharapkan oleh suatu rumah sakit (Rivai, 2004)
Hal ini didukung oleh penelitian Syarifah (2014) di Ruang Rawat Inap Kelas III RSUD Inche Abdul Moeis Samarinda, bahwa mayoritas responden mengatakan pemberian insentif yang dilakukan tergolong cukup baik 41,5\%. Tetapi dari hasil penelitian ini, ada juga responden yang menilai bahwa insentif yang diterima masih rendah hal ini dibuktikan dengan jawaban responden bahwa walaupun responden bekerja keras, insentif yang diterima tidak akan meningkat $35 \%$ serta besarnya insentif yang diterima kurang sesuai dengan harapan responden 30\%. Suwatno (2011), mengatakan faktor-faktor yang mempengaruhi besarnya insentif mencakup antara lain, jabatan atau kedudukan, prestasi kerja dan laba perusahaan. Sama halnya dengan hasil wawancara peneliti terhadap perawat bahwa besarnya insentif yang diterima perawat ditentukan oleh jabatan, pendidikan dan lama bekerja.

Menurut asumsi peneliti, setiap orang memiliki penilaian yang berbeda pada suatu hal, termasuk pemberian insentif. Seseorang dapat menilai insentif yang ia terima sudah tergolong tinggi tetapi dalam penilaian orang lain insentif tersebut masih tergolong rendah bagi dirinya. Hal ini dapat dipengaruhi oleh faktor kebutuhan hidup sehingga penilaian setiap orang berbeda-beda. Serta adanya ketidak adilan dalam pembagian insentif

\section{Kinerja Perawat}

Hasil penelitian yang dilakukan didapatkan bahwa mayoritas responden sudah melakukan pendokumentasian secara lengkap $67,8 \%$. Hal ini dibuktikan dengan analisa lembar observasi bahwa responden telah mendokumentasikan semua intervensi yang telah dilakukan di dalam status asuhan keperawatan pasien $72 \%$, menulis pada format yang baru $70 \%$, serta mengumpulkan dan mengelompokkan data bio-psiko-sosialspiritual tentang pasien $67 \%$.

Perawat yang melakukan pendokumentasian secara lengkap merupakan salah satu indikator menunjukkan kinerja yang baik. Kinerja perawat dapat diukur dari kualitas pelayanan dan asuhan keperawatan 
dengan indikatornya nilai dokumentasi keperawatan. Setiap tindakan yang dilakukan kepada pasien harus terhindar dari kesalahankesalahan dengan cara menggunakan pendekatan proses keperawatan dan pendokumentasian yang akurat dan benar sesuai standar yang berlaku (Nursalam, 2007). Hal ini sejalan dengan penelitian yang dilakukan oleh Bara (2014) di Ruang Rawat Inap RSUD Pasar Rebo. Dalam penelitian tersebut menunjukkan mayoritas responden melakukan pendokumentasian dengan lengkap $51,25 \%$. Hasil penelitian yang dilakukan oleh Pakudek (2014) Di Instalasi Rawat Inap C RSUP prof. Dr. R. D. Kandou Manado didapatkan mayoritas responden melakukan pendokumentasian secara lengkap $84,3 \%$. Tetapi ada juga responden yang melakukan pendokumentasian yang tidak lengkap, hal ini dibuktikan dengan analisa kuesioner, responden tidak membuat rencana lanjutan jika hasil tindakan asuhan keperawatan tidak memuaskan $42 \%$, tidak membuat catatan evaluasi kemampuan seluruh pasien setelah diberikan tindakan keperawatan $41 \%$. Asumsi peneliti dalam hal kelengkapan pendokumentasian dapat dipengaruhi oleh beberapa faktor diantaranya beban kerja, kurangnya pengetahuan dalam pendokumentasian, lama bekerja, pendidikan serta supervisi kepala ruangan.

\section{Hubungan Pemberian Insentif Dengan Kinerja Perawat Dalam Pendokumentasian}

Hasil penelitian didapatkan bahwa mayoritas perawat menilai pemberian insentif tinggi $69.9 \%$ dengan pendokumentasian lengkap $57,1 \%$. Hal ini sesuai dengan pendapat yang disampaikan oleh Hasibuan (2006) bahwa pemberian balas jasa yang cukup besar maka disiplin karyawan akan semakin baik dan lebih menaati peraturanperaturan yang berlaku. Jadi untuk meningkatkan kedisiplinan karyawan seorang pemimpin harus mempertimbangkan besar kecilnya pembagian insentif karena hal tersebut akan sangat berpengaruh terhadap kinerja karyawan secara khusus kedisiplinan dalam berbagai instansi termasuk di dalam rumah sakit.

Pemberian insentif dapat meningkatkan motivasi perawat. Motivasi merupakan dorongan yang berpengaruh membangkitkan, mengarahkan, dan memelihara perilaku yang berhubungan dengan lingkungan kerja. Motivasi kerja yang semakin tinggi menjadikan perawat mempunyai semangat yang tinggi untuk memberikan pelayanan yang terbaik (Mudayana, 2010). Hal ini sebanding dengan motivasi yang tinggi untuk melakukan pendokumentasian akan menghasilkan kualitas dokumentasi yang lengkap dan sebaliknya motivasi yang rendah akan menghasilakan pendokumentasian yang tidak lengkap. Hal ini didukung oleh penelitian yang dilakukan oleh Husmi (2018) dengan judul penelitian Pengaruh Kompetensi, Motivasi dan Insentif Perawat terhadap Pendokumentasian AsuhanKeperawatan Di Ruang Rawat Inap RSU Wisata UIT Makassar didapatkan bahwa ada hubungan antara insentif dengan dokumentasi asuhan keperawatan. Semakin tinggi insentif yang diberikan maka semakin lengkap pula pendokumentasian asuhan keperawatan yang akan dilaksanakan perawat.

Perawat perlu diberikan balas jasa dalam bentuk gaji, kompensasi maupun insentif. Dengan pemberian insentif tersebut akan meningkatkan minat kerja perawat dalam memberikan asuhan keperawatan termasuk dalam hal kelengkapan pendokumentasian asuhan keperawatan.

Kelengkapan pendokumentasian asuhan keperawatan merupakan salah satu tugas dan legal etik dari seorang perawat. Pemberian insentif akan menunjang kinerja perawat dalam hal kelengkapan pendokumentasian asuhan keperawatan. Berdasarkan teori dan data yang didapat, semakin tinggi insentif yang diterima perawat maka semakin lengkap juga pendokumentasian asuhan keperawatan yang dilakukan perawat. Begitu juga sebaliknya, semakin rendah insentif yang diterima perawat maka semakin tidak lengkap pendokumentasian yang dilakukan perawat. 


\section{KESIMPULAN}

1. Pemberian insentif mayoritas tinggi

2. Kinerja perawat dalam pendokumentasian asuhan keperawatan mayoritas lengkap

3. Ada hubungan Pemberian Insentif Dengan Kinerja Perawat Dalam Pendokumentasian Asuhan Keperawatan dengan nilai $\mathrm{p}$ value $0,017(\mathrm{p}<0,05)$.

\section{SARAN}

1. Bagi Responden

Dari hasil penelitian ini diharapkan perawat mampu meningkatkan kinerjanya, salah satunya dalam hal pendokumentasian asuhan keperawatan.

2. Bagi Rumah Sakit

Bagi pihak rumah sakit diharapkan mampu memberikan dukungan moril maupun materil dalam menunjang kinerja perawat baik dalam hal pendokumentasian asuhan keperawatan, serta memberikan pembinaan dan pengarahan agar melakukan pendokumentasian asuhan

---keperawatan yang lengkap

3. Bagi Peneliti Selanjutnya

Bagi peneliti selanjutnya diharapkan dapat

---menganalisa faktor-faktor yang mempengaruhi pendokumentasian asuhan keperawatan seperti beban kerja perawat, supervisi kepala ruangan, lama kerja, serta melakukan observasi langsung dengan mengikuti proses pendokumentasian yang dilakukan perawat.

\section{REFERENSI}

Bara \& Suryati. (2014). Hubungan motivasi perawat dengan pelaksanaan pendokumentasian asuhan keperawatan di ruang rawat inap RSUD Pasar Rebo. http://www.academia.edu/download/ 40839472/622_Bara_Miradwiyana Hubungan_Motivasi_Perawat_denga n_Pelaksanaan.pdf. Diakses 18 Februari 2018.

Hasibuan, M. (2006). Manajemen dasar, pengertian, dan masalah. Jakarta: PT. Bumi Aksara.

Hidayanto. (2015). Hubungan pemberian reward kepada perawat dengan pelaksanaan dokumentasi asuhan keperawatan. http://www.stikeskenda l.ac.id/journal/index.php/PSKM/artic le/view/105. Diakses 2 Juli 2018.

Hidayat, A.A. (2002). Pengantar dokumentasi proses keperawatan. Jakarta : EGC

Husmi. (2018). Pengaruh kompetensi, motivasi dan insentif perawat terhadap pendokumentasian asuhan keperawatan di ruang rawat inap RSU wisata UIT Makassar. http://journal.stieamkop.ac.id/index.p hp/yume/article/view/239. Diakses 4 Juli 2018.

Mudayana. (2010). Pengaruh motivasi dan beban kerja terhadap kinerja karyawan di rumah sakit nur hidayah bantul. http://journal.uad.ac.id/index .php/KesMas/article/view/1098.

Nursalam. (2007). Manajemen keperawatan dan aplikasinya. Jakarta: Salemba Medika

(2008). Proses dan dokumentasi keperawatan: konsep dan praktik. Jakarta: Salemba Medika.

(2011). Manajemen keperawatan: aplikasi dalam praktik keperawatan professional. (Edisi 3). Jakarta: Salemba Medika.

Pakudek. (2014). Hubungan motivasi perawat dengan pelaksanaan dokumentasi asuhan keperawatan di instalasi rawat inap C RSUP prof. Dr. R. D. Kandou Manado. https://ejournal.unsrat.ac.id/index.ph p/jkp/article/view/5165. Diakses 2 Juli 2018

Sudarmanto. (2009). Kinerja dan pengembangan kompetensi $\mathrm{sdm}$ (teori, dimensi pengukuran dan implementasi dalam organisasi). Yogyakarta : Pustaka Pelajar.

Syarifah. (2014). Hubungan pemberian insentif dengan motivasi kerja perawat ruang rawat inap kelas 3 Rsud Inche Abdul Moeis Samarinda. http://ejournal.an.fisip-unmul.ac.id /site/wp-content. 